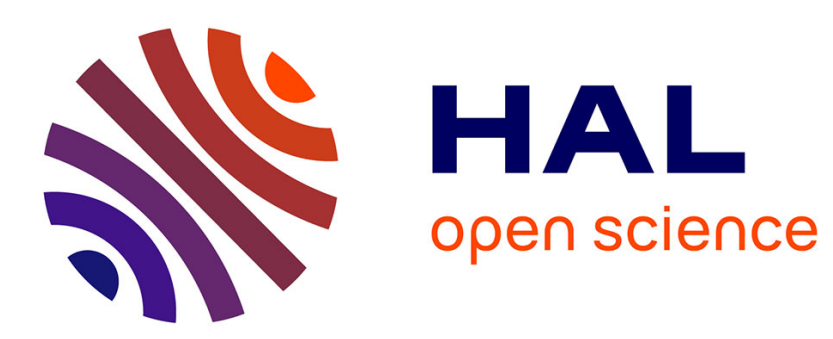

\title{
Initial and Subsequent Location Choices of Immigrants to the Netherlands
}

\author{
Aslan Zorlu, Clara H Mulder
}

\section{To cite this version:}

Aslan Zorlu, Clara H Mulder. Initial and Subsequent Location Choices of Immigrants to the Netherlands. Regional Studies, 2008, 42 (02), pp.245-264. 10.1080/00343400601145210 . hal-00514663

\section{HAL Id: hal-00514663 \\ https://hal.science/hal-00514663}

Submitted on 3 Sep 2010

HAL is a multi-disciplinary open access archive for the deposit and dissemination of scientific research documents, whether they are published or not. The documents may come from teaching and research institutions in France or abroad, or from public or private research centers.
L'archive ouverte pluridisciplinaire HAL, est destinée au dépôt et à la diffusion de documents scientifiques de niveau recherche, publiés ou non, émanant des établissements d'enseignement et de recherche français ou étrangers, des laboratoires publics ou privés. 


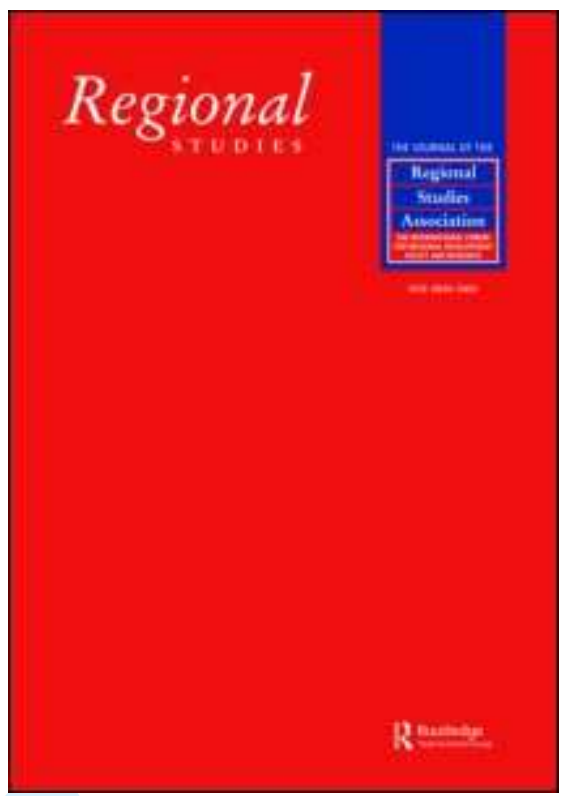

Initial and Subsequent Location Choices of Immigrants to the Netherlands

\begin{tabular}{|r|l|}
\hline Journal: & Regional Studies \\
\hline Manuscript ID: & CRES-2006-0166.R2 \\
\hline Manuscript Type: & Main Section \\
\hline JEL codes: & $\begin{array}{l}\text { F22 - International Migration }<\text { F2 - International Factor } \\
\text { Economics, J15 - Economics of Minorities and Races }<\text { J1 }- \\
\text { Demographic Economics }<\text { J - Labor and Demographic Economics, } \\
\text { R23 - Regional Migration|Regional Labor Markets|Population }<\text { R2 - } \\
\text { Household Analysis }<\text { R - Urban, Rural, and Regional Economics }\end{array}$ \\
\hline \hline Keywords: & location choice, immigrants, ethnic residential segregation \\
\hline
\end{tabular}

\section{SCHOLARONE" \\ Manuscripts}


JEL Classification: F22, J15, R23

\title{
Initial and Subsequent Location Choices of Immigrants to the Netherlands
}

\author{
Aslan Zorlu \\ Department of Geography, Planning and International Development Studies, University of Amsterdam \\ Amsterdam Institute for Advanced Labour Studies, University of Amsterdam \\ Clara H. Mulder \\ Department of Geography, Planning and International Development Studies, University of Amsterdam
}

Key words: location choice, immigrants and ethnic residential segregation

\begin{abstract}
The initial settlement behaviour and the subsequent mobility of immigrants who arrived in the Netherlands in 1999 are examined using rich administrative individual data. The study considers the settlement patterns of immigrants from various countries of origin who entered the country as labour, family or asylum migrants. The evidence suggests distinct settlement trajectories for asylum and other non-western immigrants. The presence of co-ethnics and members of other ethnic minorities, but also socioeconomic neighbourhood characteristics, appear to play an important role in determining location choice. Differences in the settlement and spatial mobility patterns of immigrants with various degrees of distance from the native Dutch in terms of human and financial capital, proficiency in the relevant language(s), and religion confirm the main predictions of spatial assimilation theory.

This research is supported by the Netherlands Organisation for Scientific Research (NWO), VICI grant no. 45304-001. The paper is part of a joint project with Statistics Netherlands; we are grateful to the Department of Total Statistics for allowing us the use of the Social-Statistical Database. We thank two anonymous reviewers of this journal for their helpful comments.
\end{abstract}




\section{INTRODUCTION}

Ethnic residential segregation is at the top of the social and political agenda in both old and new immigration countries. While residential segregation takes a prominent position in the research agenda in the US, for European cities research on segregation is scarce. Correspondingly, the segregation literature has been dominated by studies considering the residential segregation of blacks and Hispanics in the United States (SOUTH et al., 2005; QUILLIAN, 2002; CUTLER et al., 1999; BORJAS, 1998; SOUTH \& CROWDER, 1998; MASSEY et al., 1994; MASSEY \& DENTON, 1993). The small scope of research on ethnic segregation in European countries is possibly the result of the relatively low levels of ethnic segregation and the small number of mono-ethnic areas (MUSTERD, 2005).

The high concentration of ethnic minorities in certain geographical locations is widely and implicitly believed to impede the integration of ethnic minorities in host countries. Ethnic segregation is usually associated with a simultaneous concentration of educational failure, welfare dependency, low labour force participation, poverty, crime, and hopelessness. This association has raised public concern about segregation. Consequently, there is a growing interest from policymakers and scholars as some European cities continue to segregate and ethnically related violence has started to appear in some European cities such as London, Paris, and Amsterdam. Although the level of segregation and its interaction with socioeconomic factors has been studied for some European countries (MUSTERD, 2005; BOLT \& VAN KEMPEN, 2003; ANDERSSON, 1998), little is known about the role of the location choices of new immigrants in the emergence or continuation of segregation.

Previous studies on the location choices of immigrants have investigated either their initial settlement behaviour or their internal mobility, but seldom both together. This is probably the result of the lack of appropriate data and methodological difficulties associated with having to 
use cross-sectional data. These studies have mainly sought answers to the question whether immigrants' location choices are determined by economic prospects and welfare generosity (BARTEL, 1989; ZAVODNY, 1999; BEENSTOCK, 1997; ASLUND, 2005). In that research, the spatial absorption of immigrants and the economic impact of immigration were the central themes rather than the contribution of recent immigrants to ethnic segregation. This paper studies immigrants' settlement patterns upon arrival and their subsequent mobility, with an emphasis on ethnic residential segregation in the Netherlands, utilising a unique administrative longitudinal data file housed by Statistics Netherlands. It is argued that an analysis of initial location choices is only of limited significance in identifying the contribution of new immigrants to ethnic segregation, because the spatial mobility of immigrants tends to be substantial in the first years following arrival.

New immigrants to the Netherlands are a heterogeneous group, consisting mainly of family, asylum, and labour migrants. These categories of immigrants have different spatial settlement patterns induced by the presence of co-ethnics, housing market restrictions, and socioeconomic status. The location choices of family migrants are probably related to the residential locations of their family members, while the settlement behaviour of other immigrants is likely to be more sensitive to their socioeconomic position and local economic prospects. In addition, the highly regulated Dutch housing market significantly restricts the voluntary character of location choice, given the relatively weak social economic position of immigrants. We have considered institutional restrictions and the strong heterogeneity in the immigrant population. Relying on evidence from the location choice literature, the study explores the role of co-ethnics and other ethnic minority groups in the neighbourhood as well as such economic factors as average wages and unemployment on local labour markets. This approach reveals a stratified settlement and mobility pattern across immigrant groups by country of origin and migration motives. 
The study uses the neighbourhood as the spatial unit in which the concentration of nonwestern ethnic minorities is measured, since the neighbourhood is supposed to be an appropriate delineation of the spatial area in which to investigate the spatial mobility of immigrants (LOGAN et al., 2002; QUILLIAN, 2002; SOUTH et al., 2005). Initial location choices are analysed for immigrants categorised according to country of origin and migration motive (namely labour, family, and asylum migration) by regressing the number of new immigrants arriving in neighbourhoods in the Netherlands in 1999 on the characteristics of the neighbourhoods. These characteristics include the presence of co-ethnics and other ethnic minorities. Evidence of the spatial distribution of immigrants suggests that new immigrants tend to settle primarily in certain neighbourhoods of large cities where their co-ethnics are concentrated. The subsequent mobility is examined using individual data. The propensity to move to less or more highly segregated areas is studied, using three distinct levels of segregation defined by clustering neighbourhoods into native, mixed, and segregated categories based on the levels of concentration of non-western ethnic minorities. These empirical analyses provide evidence for the determinants of mobility into and from segregated neighbourhoods across ethnic groups.

\section{PREVIOUS RESEARCH AND HYPOTHESES}

Empirical studies on the location choice behaviour of immigrants usually focus either on the location choice upon arrival (ZAVODNY, 1999) or on their migration patterns in the host country (MASSEY et al., 1994; NOGLE, 1994; BEENSTOCK, 1997; SOUTH et al., 2005). Only a few studies combine immigrants' initial location choice and subsequent mobility in a longitudinal perspective (BARTEL, 1989; BEENSTOCK, 1997; ASLUND, 2005). The literature suggests that the presence of other immigrants is the primary determinant of immigrants' location choices. Local labour market conditions and welfare generosity seem to play a minor part in determining these choices (BARTEL, 1989; ZAVODNY, 1999; 
BORJAS, 1998, 1999; KAUSHAL, 2005; ASLUND, 2005). The tenor of the location choice literature is that the propensity to migrate varies directly with education and inversely with age. Highly-educated immigrants are much more mobile and dispersed and have smaller probabilities of migration towards highly segregated areas. Furthermore, within the United States immigrants tend to migrate more frequently than natives do.

European research on the location decisions of immigrants is scarce. A recent study by ASLUND (2005) investigates the initial and subsequent location choices of refugees and OECD migrants across municipalities in a natural experimental setting in Sweden. The study underlines the main findings of studies from the United States that the presence of co-ethnics and a large overall immigrant population has a significant role in determining initial location choices and relocation decisions. The study also confirms the role of local economic prospects in attracting immigrants. A shift from locations with small populations towards locations with large populations is also observed. ASLUND also presents evidence that immigrants' location decisions are affected by labour market prospects. Immigrants tend to move from municipalities with high unemployment rates to municipalities with lower unemployment rates and higher earnings. At the same time, ASLUND also finds that there are concentrations of immigrants in municipalities with a relatively large number of welfare recipients; he puts no explanation forward for this finding. BOLT and VAN KEMPEN (2003) examined the mobility of Surinamese, Turks, and Moroccans from and into poverty neighbourhoods in the Netherlands. These authors show that these groups have a greater probability of moving into poverty neighbourhoods and a smaller probability of escaping poor neighbourhoods compared with native Dutch. They suggest that a combination of a higher income and higher education increases the probability of moving out of poverty neighbourhoods. Although a poor neighbourhood may not necessarily be ethnically segregated, the opposite is often true: 
ethnically segregated areas are often inhabited by people in a relatively poor socioeconomic position (MUSTERD, 2005).

The residential settlement behaviour of immigrants can be studied with the aid of assimilation theories that describe a process through which immigrants adopt the attitudes and ways of life of the dominant society and obtain a similar socioeconomic position. Spatial assimilation, which is regarded as an ethnic group's geographical proximity to the majority group, is seen as an important stage in this general process. Assimilation is thought to follow social mobility in terms of achievements in education, income, and occupational status (MASSEY \& MULLAN, 1984; MASSEY \& DANTON, 1985). Residential proximity between an ethnic minority group and the majority group probably enhances a variety of cross-ethnic relationships that are relevant in the achievement of greater social mobility. Spatial assimilation theory has been widely applied to enhance our understanding of the residential patterns of immigrants in North America (SOUTH et al., 2005; FONG \& WILKES, 1999). Recent empirical evidence suggests that social mobility does not necessarily lead to spatial assimilation. This appraisal led to a modification of the classical assimilation model, often referred to as segmented assimilation. The segmented assimilation perspective suggests that various ethnic groups experience different assimilation patterns given their human and financial capital endowments and proficiency in the dominant local language (SOUTH et al., 2005).

\section{Spatial assimilation}

Spatial assimilation theory was originally developed to interpret the settlement behaviour of voluntary labour immigrants, mostly from Europe, who arrived in the United States in the early part of nineteenth century. The relevance of this theory is unclear, however, for the behaviour of other types of immigrants: the family and asylum migrants, for example, who 
have comprised a significant part of the immigration flows to Europe since the 1980s. Spatial assimilation theory suggests a number of hypotheses that we have tested for new immigrants to the Netherlands. First, new immigrants are expected to settle primarily in neighbourhoods where co-ethnics are concentrated. A preference for residing in a neigbourhood inhabited by people from the same country of origin could stem from the supply of specific ethnic goods and services or from easier access to host-country-specific information through ethnic networks. Preferences might also be related to such factors as prejudice, fear of discrimination or neigbourhood problems (LOGAN et al. 2002). The typical new immigrant is able to utilize the help of co-ethnics in obtaining access to housing and labour markets as well as to ethnically-specific goods and services.

Spatial assimilation theory also implies that similarities between the Dutch community and immigrant groups enhance the residential integration of immigrants within the host country. Human capital endowment, proficiency in the local language, and religion are important approximates for distance from the host country population. In that sense, immigrants from Surinam (a former Dutch colony) are likely to have a closer distance from the native Dutch, since they share a similar cultural and religious background and most Surinamers already speak Dutch on their arrival. The cultural distance between western immigrants or labour migrants and the Dutch can also be seen as relatively small in terms of human capital endowment, religious background, and proficiency in English, which is widely spoken in the Netherlands. At the other extreme are the immigrants from non-western countries such as Turkey, Morocco, Iraq, Somalia, and Iran. They are more likely to be asylum seekers and family migrants and may have a greater cultural distance from Dutch society, although in various degrees.

The second hypothesis concerns the relationship between settlement behaviour and cultural distance: the shorter their distance from the native Dutch, the more likely are immigrants to 
settle initially and move subsequently into a less segregated neighbourhood. When immigrants are categorized by migration motives, we would expect to find a strong effect from the presence of co-ethnics on the location choice of new family immigrants. The effect could be expected to be smaller for those, such as asylum migrants and students, who had no large close ethnic communities in the Netherlands. The effect was expected to be less strong for immigrants from western countries, because this group contains labour immigrants and their family members.

Since information on the level of education of immigrants is not included in our data, employment status has been used to approximate human capital endowment and the social mobility of immigrant groups. Our hypothesis was that employed immigrants move to less segregated neighbourhoods and unemployed immigrants move in the opposite direction.

Spatial assimilation theory suggests that immigrants initially settle in ethnic enclaves where the environmental quality of the neighbourhood is poor. In the Netherlands, regional differences in wages are small and the strength of the association between ethnic segregation and economic success is doubtful (MUSTERD, 2003). This implies that the local mean wage, unemployment and house values are rather more likely to refer to a better quality of housing and neighbourhood. Immigrants with more human and financial capital, like labour migrants, are hypothesised mainly to choose neighbourhoods where income and house values are high and unemployment is low. The location choice of family migrants could also be expected to be affected by local labour market conditions, although less so than for labour migrants. Local labour market conditions are less likely to affect family migrants directly, but they may be effective through the family members who have invited them. The location decisions of asylum immigrants were not expected to be sensitive to local labour market conditions because they are primarily admitted on the base of humanitarian reasons. 


\section{Housing market restrictions}

In the Dutch housing market, about half the housing stock consists of rental accommodation, most of which belongs to the social housing sector. The access to social housing is constrained by institutional regulations. Only households with an income below a certain limit are allowed to rent a home in this sector. Additionally, the probability of being eligible for a rental home is directly related to the duration of residence in the municipality. Social housing is concentrated in certain neighbourhoods of large cities and rents in this sector are below market prices. These restrictions induce rationing and lead to a long waiting time for potential renters. This system is clearly unfavourable for those seeking housing from outside the municipality and could influence new immigrants particularly adversely since migrants need to find their first home within a very limited time period with limited information about the local housing market. To capture the effects of housing market restrictions, we used two indicators: the fraction of homeowners in the neigbourhood and the share of the social sector in the municipality. The effect of the share of homeowners was expected to be positive, because it indicates the relative size of the private housing sector, which is not subject to institutional barriers. The effect of the size of the social sector was expected to be negative, because it indicates the extent of the sheltered housing market in the municipality.

The impact of all these variables may vary across immigrant groups. The initial location decisions of new immigrants may be associated with their host country contacts, which may be related to their migration motives. Many immigrants enter the Netherlands on the basis of family reunification or formation, so their residential locations are in fact predetermined: they join existing households. The location choice of family immigrants will not be influenced directly by local housing market restrictions. But, in contrast, the settlement decisions of labour and asylum migrants are likely to be affected by restrictions and opportunities on the local housing market as well as economic factors. Labour migrants, who are often from 
western countries, may have been recruited abroad and their initial location is likely to be determined by their job. These people are likely to live close to the company for which they work. So, their location choices are likely to be associated with local economic conditions. These immigrants are relatively prosperous and many of them will be able to afford to rent in the private part of the housing market. On the other hand, asylum migrants are a priori restricted to the cheap rental housing market. They are obliged to participate in an admission procedure, which takes one to three years. Usually, while they are involved in this procedure, they are obliged to reside at an assigned location and are not registered in the population register: only a small fraction of asylum seekers (about 10 percent) is registered while still in the procedure. After receiving legal status, they register in the population register to be eligible for public services. They are then entirely free to choose their new residential location. Most immigrants from developing countries may be assumed to arrive without any financial assets. While these immigrants have to manage without family support, they are effectively excluded from owner-occupied housing and the more expensive part of the rental sector. They are forced to look for a cheap rental home in a cheap neighbourhood.

\section{DATA AND DESCRIPTIVE STATISTICS}

We used a rich register data file housed at Statistics Netherlands (the Dutch Social-Statistical Database, SSD) and including all legal residents of the Netherlands. Our sample covers all immigrants (foreign-born persons with non-Dutch parents) who arrived in 1999 and were present on the third Friday of September 1999, which is the measurement moment for these data. Subsequently, we followed these individuals for four years: from 1999 to 2003 . The data contain longitudinal information about residential locations at neighbourhood level, indicators of socioeconomic and household status, housing conditions, and some neighbourhood characteristics. Although the literature emphasises the key role of education in explaining 
location decisions, unfortunately the impact of education on immigrants' settlement behaviour could not be explored in this study.

We used the neighbourhood as the geographical unit of analysis. This is the smallest unit defined in the data, with on average about 1900 residents in 1999, given the total population was about 15.7 million and the number of neighbourhoods suitable for analysis was 8275 . This strategy provides several advantages. First, such a small size of spatial unit enabled us to account for the great variation of shares of ethnic minority populations in the neighbourhoods of larger cities. Second, neighbourhoods are in fact small spatial areas where interactions between people of different origin are likely to occur. Third, using the smallest areas provides maximum flexibility to cluster these areas on the basis of our own criteria, in our case degrees of ethnic concentration.

Table 1 gives the mean values of the variables by country of birth for immigrants from six selected countries, one year after the immigrants' official settlement in the Netherlands. The data we used range from 1999 through 2003, so we selected the year 2000. We chose it, because the labour market position of immigrants is more representative one year after arrival, while their geographical distribution is close to that on arrival ${ }^{\mathrm{i}}$. More than 1100 of these immigrants entered the Netherlands in 1999. They were Afghanis, Chinese, Iraqi, Surinamese, Turks, and Moroccans. In the Netherlands, Surinamese, Turks and Moroccans comprise the largest communities. New immigrants from these countries usually come to the Netherlands on the basis of family ties. Immigrants from Afghanistan and Iraq mainly enter as asylum seekers; there is no large community of Iraqis or Afghanis in the Netherlands. The Chinese take an intermediate position; new Chinese immigrants were allowed to enter for a variety of reasons in 1999. Non-western immigrants are a highly heterogeneous category, comprising immigrants entering the Netherlands for a variety of migration motives. The rest of the immigrants are clustered into two categories: other non-western and western. 
Alternatively, for the analyses of initial location choices, immigrants are categorised by migration motives as assessed by the Immigration and Naturalisation Service (IND) at entry. Four main migration motives are distinguished: labour, asylum, family reunification, and family formation. Although the migration motive may include some measurement error ${ }^{\mathrm{ii}}$, this variable was expected to play an important part in explaining the location decision. Table 1 indicates a strong association between country of birth and migration motive. There are substantial differences in the individual and household characteristics as well as in the spatial distribution of immigrants by country of birth. Turkish, Moroccan, and Surinamese immigrants are usually family migrants. Asylum migrants come mainly from Afghanistan, Iraq, and other non-western countries. Labour migrants are predominantly from western countries. Immigrants from non-western countries tend to be younger, renters rather than homeowners, more frequently unemployed, and residing in locations where unemployment is relatively high and wages and house values are low. Immigrants from Afghanistan and Iraq, who are usually asylum migrants, are more often young males. They are often unemployed and live in a single-person household, while immigrants from Turkey, Morocco, and Surinam more frequently live in a couple household.

Immigrants predominantly settle in large cities. Table 1 shows that almost 59 percent of Surinamese and 51 percent of Moroccans were located in the four largest cities one year after arrival, with a clear preference for Amsterdam. Among the immigrants from the classic countries of origin in Dutch immigration history, the Turks are relatively more diffused. Immigrants from Iraq and Afghanistan who entered the country as asylum seekers and who do not have a large community of co-ethnics in the Netherlands are scattered over the country. This dispersion is probably the result of the proactive government refugee settlement policies applied during the period between the asylum application and admission, after which refugees are free to move. Chinese immigrants, for whom there is no single particularly dominant 


\section{DETERMINANTS OF INITIAL LOCATION CHOICES}

Because we do not have any information about the socioeconomic background of immigrants prior to immigration, we have focused on the characteristics of neighbourhoods and used a simple linear regression model to study the determinants of the settlement behaviour of immigrants groups distinguished by country of birth and, alternatively, by migration motive. The unit of analysis is the neighbourhood, so there is no opportunity to control for the individual characteristics of the migrants. In the analysis of further moves, we were able to perform a limited number of controls: we could control for gender, age, housing tenure, household composition, and employment status. No information about level of education was available, however.

The number of immigrants settling in a neighbourhood is regressed on the demographic and socioeconomic characteristics of neighbourhoods and municipalities: 
$I_{i}=\alpha+N_{i} \beta+M_{i} \delta+\varepsilon_{i}$

where $I_{i}$ is the number of immigrants in neighbourhood $i$ who entered the Netherlands in 1999. $N_{i}$ is a vector of neighbourhood characteristics that include the shares of the largest ethnic minority groups (Moroccan, Turkish, Surinamese/Antilleans, other non-western and western), the fraction of owner occupied homes, the share of social housing, the size of neigbourhood population, and the logarithm of the average wages for earned income.

$M_{i}$ is a vector of municipality characteristics covering local labour market conditions in terms of fractions of the medium- and highly-skilled labour force, as well as the unemployment rate. Additionally, the mean value of all homes in the municipality (rented and owner-occupied) is included to control for housing market conditions and the size of the municipal population to capture large municipality effects. We have also used fixed effects for the four largest cities.

Equation 1 was estimated for the seven separate immigrant groups by country of birth. Additionally, separate models were estimated for labour and asylum migrants, and for family migrants from Turkey, Morocco, and Surinam. Because neighbourhoods are nested in municipalities, we relaxed the assumption of the independent observation of the neighbourhoods by correcting for a possible correlation of standard errors for neighbourhoods within a municipality. The estimation results are reported in Tables 2 and 3. In addition to the coefficients, the standardised (beta) coefficients are also presented to show the relative strength of the covariates used. Immigrants' initial settlement patterns seem to be strongly associated with neighbourhood prosperity in terms of logarithmic mean value of houses, as proposed by spatial assimilation theory. There is an inverse relationship between the number of immigrants entering a neighbourhood and house values. This relationship is particularly strong for almost all immigrant groups from non-western countries. The inverse effect of neighbourhood prosperity is smallest for Surinamese and western immigrants. The results 
unambiguously confirm the findings from the international literature that immigrants' location choices are largely determined by the fraction of the neigbourhood population made up by ethnic minorities from the same origin. This association is the strongest for immigrants from Morocco, who have large communities of co-ethnics in the Netherlands. A one standard deviation increase in the fraction of Moroccans in the neighbourhood leads to a 0.39 standard deviation increase in the predicted number of Moroccan immigrants settling in the neigbourhood. The association between the residential location of Turkish immigrants and their co-ethnics is remarkably weaker than for Moroccan immigrants. This association is comparable with the association for western immigrants. A one standard deviation increase in the share of Turkish and western people results in a 0.24 and 0.17 standard deviation increase in the number of immigrants from the same country of origin. The location choices of immigrants from China, Iraq, and Afghanistan are associated positively with the share of nonwestern ethnic minorities, but this association is less pronounced than for the other groups mentioned. No association was found for the residential location of Surinamese immigrants and their co-ethnics. This outcome is closely related to the estimation procedure: when the independent observation of neighbourhoods is assumed, a strong association is found for the Surinamese. The association is the strongest for them of all the groups, despite the nested nature of neighbourhoods within the municipality. This association is probably related to the strong concentration of Surinamese in Rotterdam and Amsterdam.

The relative size of a particular ethnic group in a neighbourhood is associated with the destination location of groups other than immigrant co-ethnics in various ways. The number of Turkish immigrants is positively related to the concentration of Moroccans in the neigbourhood in addition to the association with the presence of co-ethnics. Moroccan immigrants settle more frequently in the neighbourhoods where Surinamese are concentrated, and notably not in the neighbourhoods where Turks are clustered. This is a remarkable 
outcome, because there are religious and socioeconomic similarities between Turks and Moroccans, while Surinamese differ from these groups in their religious and linguistic background as well as in their migration history (Zorlu \& Hartog, 2002). Our prediction for Surinamese immigrants in that sense is confirmed: the initial location of Surinamese immigrants is not associated with the concentration of Turks and Moroccans. There is an adverse relationship between the number of immigrants from western countries entering a neighbourhood and the concentration of Surinamese/Antilleans, Turks and Moroccans. Conversely, Turkish, Moroccan, and Surinamese immigrants are less likely to settle in neighbourhoods where western immigrants are concentrated. This pattern emphasises the strong effect of ethnic ties and socioeconomic dissimilarities between western and nonwestern immigrants, given all other restrictions and housing market rigidities that seriously constrain a free choice of residential location.

The results also indicate that the initial location of immigrants from the Turkish and Moroccan groups is more often a neighbourhood where the proportion of people living in an owner-occupied home is relatively high. A greater number of Afghan immigrants is positively associated with the prosperity of the neighbourhood as measured by the average wage level for earners. This relationship seems remarkable considering their socioeconomic position but understandable because an overwhelmingly large share of them entered the Netherlands as asylum migrants who were subject to government settlement policies, rather than being able to make their own location choices. Alternative models estimated for these groups indicate that the number of Turkish and Moroccan immigrants is negatively associated with the income level in the neighbourhood when the effects for the ethnic composition of neighbourhoods are not controlled (not shown here). This result implies that there is a positive association between the settlement behaviour and the neighbourhood prosperity, even for Turkish family migrants, given the ethnic composition of the neighbourhood. As a matter of 
course, the effect of the neighbourhood population variable is positive and highly significant for all the groups. Another interesting finding is the strong inverse relationship between the mean value of the homes in a neighbourhood and the number of immigrants from any origin. Immigrants evidently tend to locate initially in neighbourhoods with cheap housing stock.

The lower panel of table 2 reports the effect of the variables on the municipality level. Turkish, Moroccan, and Afghan immigrants are more likely to settle in municipalities with low unemployment levels, which suggests their sensitivity to local economic conditions. The settlement behaviour of other groups seems to be insensitive to economic indicators. Furthermore, Moroccan, Chinese, and western immigrants settle more frequently in municipalities where a relatively large share of the labour force is highly skilled. Because Moroccan and Chinese immigrants are on the whole less skilled than the native Dutch, this marked association probably indicates that Moroccan and Chinese immigrants look for job opportunities complementary to the highly-skilled labour force in the local labour market. The more highly-skilled western immigrants may search for jobs requiring high skills, in competition with the highly-skilled among the native Dutch. As expected, the controls for the largest Dutch cities are often highly significant. However, the effects vary across the groups. Turkish and Moroccan immigrants and western migrants seem to be concentrated in Amsterdam, Rotterdam, and The Hague, while the Surinamese are only concentrated in Amsterdam and Rotterdam. Only western immigrants are more often found in Utrecht. The other groups are diffused over the country.

The determinants of initial locations were also investigated for separate migration motives to obtain a more detailed picture of settlement patterns. To retain large enough numbers of observed migrants to estimate the models by motive, we had to sacrifice considerable detail with regard to country of origin. Labour migration and asylum migration were analysed for all countries of origin together. Because those migrating for family reunification or family 
formation came mainly from Turkey, Morocco, and Surinam and there were enough family migrants from each of these countries, we could estimate separate models for family-related motives for these three countries. Table 3 reports the results. Labour migrants, frequently coming from western countries, choose those neighbourhoods with higher levels of earnings and higher concentrations of ethnic minority groups from western and other non-western countries. The settlement pattern of asylum migrants is strongly influenced by the share of other non-western immigrants but negatively influenced by the share of Surinamese. The location decision of asylum migrants is apparently not influenced by good economic prospects: asylum migrants are more frequently located in municipalities with higher unemployment rates.

Estimations for family migrants are specified for the two separate motives of family migration: family reunification and family formation. This is because these two groups are expected to differ in their age and skill distributions and in their dependence on fellow migrants. Those migrating for family reunification are generally younger and possibly more dependent on their family, while those migrating for family formation are usually young adults. Interestingly, the settlement patterns of Turkish and Moroccan family migrants show strong similarities: those who entered the Netherlands on the basis of family reunification seem to be slightly less sensitive to both the presence of co-ethnics and the economic indicators of the residential location (mean wage and unemployment rate). This outcome does not conform to the expectation that immigrants with a family reunification motive settle more frequently in neighbourhoods where their co-ethnics are concentrated. This finding might be the case for immigrants entering on the basis of family reunification to join a family that has moved to a less segregated neighbourhood after improving the household's economic position. Among Surinamese immigrants, no differences were observed across the types of family migration. 
Additionally, we estimated all models including expenditures and taxes of municipalities, which were supposed to measure the economic attractiveness of the municipality. These variables did not improve the models, in contrast with what some American research suggests (BORJAS, 1999). The much smaller differences between residential areas in the Netherlands than between those in the United States could explain the modest role of these factors here.

\section{Robustness of Estimations}

Because some neighbourhoods attract no immigrants and the number of immigrants clustered into groups is sometimes smaller than the number of neighbourhoods, we estimated regression equations for the sub-samples, covering only neighbourhoods to which immigrants from the relevant group had immigrated, to check whether a heteroscedasticity problem had occurred. This procedure generated larger coefficients for the covariates of neigbourhood ethnic composition and some other covariates with higher significance levels, as we expected. However, this approach ignores those neighbourhoods without any members of the relevant group as an option that an immigrant could choose. Consequently, this approach generates an overestimation of a neighbourhood's ethnic composition and other covariates. We therefore preferred estimations that included all neighbourhoods, but at the same time we corrected for a possible heteroscedasticity problem and presented corresponding robust standard errors.

Another important issue is that the separate estimations of equation 1 for immigrant groups implicitly assume that the error terms of the separate regressions are uncorrelated, which might not be the case. We therefore also estimated the set of multiple regression equations for the immigrant groups simultaneously, allowing for correlation among the error terms of the multiple equation system. This method generated results that were very similar to those of the separate estimations presented and discussed above. 


\section{$<$ TABLE 2>>}

\section{$<<$ TABLE 3 $>>$}

\section{SUBSEQUENT GEOGRAPHICAL MOBILITY}

\section{Descriptive results}

Table 4 reveals a substantial geographical mobility among immigrants in the first years after their entrance in 1999 up to 2003 . The share of movers, and particularly the share of movers between municipalities, is remarkably large compared with the total population of the Netherlands. About 8 percent of the total population moves annually, with two thirds remaining in the same municipality. Non-western immigrants move more frequently than western immigrants: about 20 percent versus about 15 percent annually. Chinese, Surinamese, and Iraqis changed their residential location particularly frequently. The frequency of moves generally shows a rising trend in the first two years. It is also interesting to note that Turkish, Moroccan, and Surinamese immigrants move more often within the same municipality, whereas Iraqis and Chinese tend to move between municipalities. When immigrants are distinguished by migration motive, asylum migrants are found to be the most frequent movers; they move relatively more often between municipalities.

\section{$<<$ TABLE 4>>}

To investigate the dynamics of ethnic segregation, we constructed three types of neighbourhood: native, mixed, and segregated. A classification into separate types was necessary, because we wished to estimate the transition probabilities between separate neigbourhood types. The distinction between the types is based on the level of ethnic 
concentration in the neighbourhood. The fraction of ethnic minorities from non-western countries in the population of the Netherlands is about 10 percent, so this percentage was used as the demarcation line between native and mixed neighbourhoods. Segregated neighbourhoods are those in which non-western ethnic minorities make up at least 35 percent of the neigbourhood population. This definition follows the criterion of 4 standard deviations used by MUSTERD and DE VOS (2005). Mixed neighbourhoods are those with an ethnic minority population of between 10 and 35 percent.

Since we were interested in the dynamics of segregation, we tracked the relocation behaviour of individuals living in a certain type of neigbourhood to the other two neighbourhood types and the same type. Considering movers only, the probabilities of moving from one type of neighbourhood to another type are given by a 3x3-dimensional matrix $(\mathbf{P})$. Each row represents the probabilities of ending up in each of the three destination-neighbourhood types when moving from an origin neighbourhood type. Thus, the rows of this matrix each add up to one. The matrix is formally given as

$$
\mathbf{P}=\left[\begin{array}{lll}
p_{N N} & p_{N M} & p_{N S} \\
p_{M N} & p_{M M} & p_{M S} \\
p_{S N} & p_{S M} & p_{S S}
\end{array}\right], \quad \text { with } \quad \sum_{i, j=1}^{3} p_{i j}=1
$$

where the subscripts attached to the probabilities ( $\mathrm{N}, \mathrm{M}, \mathrm{s})$ refer to the neighbourhood segregation types native, mixed, and segregated and the probability of being in any particular state, $p_{i j}$ at time $t+1$ depends on the state at the previous time, $t$, given as $P\left(p_{i j(t+1)} \mid p_{i j(t)}\right)$.

Table 5 shows the origin-destination matrix for mover person-year within the period 1999 to 2003 by country of birth and migration motive. The propensity to move from native and mixed neighbourhoods to segregated neighbourhoods is the highest for Surinamese and Moroccans. Immigrants from non-western countries who reside in segregated neighbourhoods are more likely to move to another dwelling within the same neighbourhood 
type. This pattern is particularly strong for Turkish, Moroccan, and Surinamese immigrants, for whom the probabilities of moving to a native neighbourhood are very small. When migration motives are considered, a relatively high probability of moving from native to segregated neighbourhoods is observed for asylum migrants and students. The relatively greater mobility from segregated to less segregated neighbourhoods for Iraqis than for Afghanis is striking, but remains hard to explain with the information available on the similarity of their backgrounds (HARTOG \& ZORLU, 2005). Family migrants residing in segregated neighbourhoods are less likely to move to native neighbourhoods.

\section{$<<$ TABLE 5>>}

Table 6 decomposes movers into those moving within and between municipalities. The propensity to move within the same neighbourhood type is particularly strong when immigrants move within a municipality: the shares are around 60 and 70 percent for native and segregated neighbourhoods respectively. The probability of moving between native and segregated neighbourhoods is very small, although immigrants are more likely to move to more segregated areas than from segregated to native neighbourhoods. When movers between municipalities are considered, movers are more likely to move to other neighbourhood types: There is a greater mobility from less to more segregated neighbourhoods and particularly in the opposite direction: that is, from segregated neighbourhoods to mixed and native neighbourhoods. 


\section{$<<$ TABLE 6>>}

The mobility patterns of new immigrants cannot be fully described by considering movers alone. The distribution of non-movers over a neighbourhood is also an important factor. Table 7 gives the initial distribution of immigrants upon arrival and the net changes in the relative share of immigrants in the different neighbourhood types. It is evident that the relative share of immigrants living in native neighbourhoods declines for all immigrant groups, while the relative shares of mixed and segregated neighbourhood increase for almost all groups, except the Chinese and Surinamese. The decline in the share of immigrants living in native neighbourhoods is the strongest for Afghanis, followed by Iraqi and other non-western immigrants. Furthermore, the decrease in the share of Chinese living in mixed neighbourhoods is remarkable, as is the decrease in the relative share of Surinamese as a single group in segregated neighbourhoods.

\section{$<<$ TABLE 7>>}

\section{The Model}

We assume that, in the years following arrival, an immigrant has a variety of location options available from which to choose, regarding the initial location as the starting point. Staying in the original location is also an option.

Consider the time periods elapsed since the immigrant arrived. Each period is a discrete time interval of 1 year with the measurement moment in September. The location choices of immigrants are first observed for September 1999 and subsequently for each year up to 2003. Corresponding with these time periods, the vector of location choices of an individual $i$ is given by 
$\left(k_{i 0}, k_{i 1}, k_{i 2}, k_{i 3}, k_{i 4}\right)$

where $k_{i j}$ is the location chosen by individual $i$ at time $j$. The probability of being observed in $k_{1}$ in time period 1 is conditional on the first location, $\operatorname{Pr}\left(k_{1} \mid k_{0}\right)$. This implies that individuals living in a particular neighbourhood type evaluate the expected utility of their moving elsewhere on the basis of information gathered for the place. Considering the three types of neighbourhood distinguished as the possible choices, the probability that an individual is observed in $k_{2}$ in period 2 is the sum of the probabilities that the individual moves to any of the 3 alternatives in period 1 multiplied by the probability that the individual moves from this location to $k_{2}$ in period 2. Correspondingly, the probabilities in periods 3 and 4 are conditional on the preceding periods. The probability that the individual is observed in $k_{4}$ in the last period, period 4 is

$\operatorname{Pr}\left(k_{4} \mid k_{0}\right)=\sum_{k_{3}=1}^{3} \operatorname{Pr}\left(k_{4} \mid k_{3}\right) \sum_{k_{2}=1}^{3} \operatorname{Pr}\left(k_{3} \mid k_{2}\right) \sum_{k_{1}=1}^{3} \operatorname{Pr}\left(k_{2} \mid k_{1}\right) \operatorname{Pr}\left(k_{1} \mid k_{0}\right)$

The neighbourhood types are assumed to be independent and unordered alternative locations. While this assumption may not be totally realistic for each individual migrant, it has the great advantage of enabling the probability of ending up in a certain location to be modelled using a multinomial logistic regression model. Let us define the probability of being observed in each destination neighbourhood $p_{i j t}$ in time $t$ based on the neighbourhood type of origin $j$ and characteristics of immigrants in time $t-1$ as follows:

$$
\ln \left(p_{i j t} / p_{i 0 t}\right)=\phi+X_{i(t-1)} \lambda+N_{i(t-1)} \eta+v
$$

where $p_{i j t} / p_{i 0 t}$ is the odds that the individual $i$ is observed in the $j$ th neighbourhood category at time $t$ relative to not moving (staying in the origin neigbourhood type $_{0}$ ) at time $t$. A vector of the characteristics of individuals and the locations where individuals lived at time $t-1$ is given by $X_{i(t-1)}$ and $N_{i(t-1)}$. Since individuals are likely to base their decisions on the information 
available at time $t-1$, all covariates are lagged by one year, which also helps to avoid endogeneity bias.

Since we are interested in the individual determinants of moves from and to more segregated neighbourhoods, multinomial logistic regression models have been used to estimate the individual determinants of transition probabilities of moving from an origin neighbourhood to another neighbourhood. An individual i's contribution to the likelihood function in the individual's residential location $j$ at the end of year $t-1$ is given by the standard form of the multinomial logit model:

$$
P_{i j t}=\exp \left(X_{i(t-1)} \lambda_{j}+N_{i(t-1)} \eta_{j}\right) / \sum_{k=1}^{3} \exp \left(X_{i(t-1)} \lambda_{j}+N_{i(t-1)} \eta_{j}\right)
$$

The estimation strategy is as follows. First, immigrants are observed in the separate neighbourhood types of native, mixed, and segregated in period $t-1$. Subsequently, for each of these sub-samples, the transition probabilities relative to staying in the origin category are estimated separately by a standard multinomial logistic regression procedure. Our dependent variable has four response categories: native, mixed, segregated, and staying, which is the reference category. Although equation 3 suggests that the probability of being observed in a neighbourhood type in time $t$ is correlated with the location in time $t-1$, we have ignored these correlations, because these transition probabilities are hard to construct and to estimate for more than two response categories.

We simply estimated the probabilities of being observed in each destination neighbourhood type based on the neighbourhood type of origin, using the pooled data for 1999-2003. To assess whether this simplification was justified, we also estimated the probabilities separately for each year of observation. This procedure generated very similar results. Since individuals contribute to the analysis up to four times, the standard assumption of the stochastic independence of error terms is violated. The models were therefore estimated with corrections 
for multiple observations for an individual to ensure that standard errors were not biased. Furthermore, we are aware that parents usually make location decisions and children have no direct influence on them. Estimations are therefore restricted to the population aged 18 years and older, because no identifier for the household is included in the data. We believe that sufficient account is taken of the absence of a household identifier by using controls for household type together with age in a flexible functional form.

\section{Model results}

The results for the three sub-samples are reported as relative risk ratios in table 8 . The most important result is the clear pattern of concentration into more segregated neighbourhoods among immigrants from non-western countries, given all the individual and neighbourhood characteristics in the models. Those who settled initially in a less segregated neighbourhood tend to move towards more segregated neighbourhoods in the four consecutive years, which confirms the findings of ASLUND (2005). This pattern is particularly strong for asylum migrants, who move the most frequently of all the immigrant groups. Asylum migrants are followed in intensity of mobility by Surinamese, Moroccan, and Turkish immigrants, who also tend to move into more segregated neighbourhoods. Bearing in mind that asylum migrants are initially much more diffused over the country, while immigrants from Turkey, Morocco, and Surinam are initially already concentrated in more segregated neighbourhoods, it would therefore seem that asylum migrants 'catch up' with other non-western immigrants in terms of concentration. It is remarkable that the concentration of Surinamese, Moroccan, and Turkish immigrants continues in the first few years after arrival, although the tendency does not necessarily persist over a longer period. Evidence from traditional immigration countries indicates a turn after the initial tendency of moving into more segregated areas (FUNKHOUSER, 2000). 
As reported above, asylum migrants move most frequently irrespective of the neighbourhood type in which they reside and their destination neighbourhood type is more likely a more segregated neighbourhood. When the residential location of asylum migrants upon arrival is in a native neighbourhood, they are about 1.5 times more likely to move within the same neighbourhood type as are labour migrants (the reference category), and respectively 2.9 and almost 8.3 times more likely to move into a mixed or a segregated neighbourhood type. If they have already settled in a mixed neigbourhood, they are almost 1.4 times more likely to move a neighbourhood type that is not more segregated than their initial neighbourhood. However, they have a 3.2 times higher probability of moving into a segregated neigbourhood. If immigrants who entered the Netherlands on the basis of family formation or family reunification settled initially in a native or mixed neighbourhood, they have a higher probability of moving into neighbourhoods with a higher degree of ethnic segregation. Those who settled in a segregated neighbourhood are the most likely to remain in the same neighbourhood. Those forming family are in that case less likely to move to native neighbourhoods.

Surinamese, Moroccan, and Turkish immigrants living in a native neighbourhood are respectively about $1.9,1.9$, and 2.1 times more likely to move to mixed neighbourhoods, and 2.9, 3.8, and 3.3 times more likely to move to segregated neighbourhoods than are western immigrants (the reference group). If Surinamese, Moroccan, and Turkish immigrants live in a mixed neighbourhood, they are 5.8, 3.5 and 3 times more likely to move to a segregated neighbourhood than are western immigrants, while the relative probabilities of moving into a native neighbourhood for Moroccan and Turkish immigrants are about 0.5 and 0.6. When these immigrants have already settled in a segregated neighbourhood, they are more likely to stay in the segregated neighbourhood. If they move, they do so more often to another segregated neighbourhood. A similar pattern holds for immigrant groups from other non- 
western countries such as Iraq, Afghanistan, and China, but for them the effects are less strong.

The estimated differences in the residential mobility patterns of immigrant groups confirm some predictions of spatial assimilation theory. The probabilities of moving into a more segregated neighbourhood are relatively low for immigrants from western countries; these people are supposed to be at a shorter distance from the native Dutch. The probabilities of moving from native into more segregated neighbourhoods are also lower for Surinamese immigrants than for non-western immigrants, while the converse holds for Surinamese residing in mixed and segregated neighbourhoods. Strikingly, neither group has a smaller probability of moving into less segregated neighbourhoods, while Turkish and Moroccan immigrants have a stronger tendency to move towards more segregated neighbourhoods: the probabilities of moving into a more segregated neighbourhood are significantly greater and the probabilities of moving into a less segregated neighbourhood are smaller.

One may ask whether the ethnic composition of the initial neighbourhood where an immigrant settled upon arrival has any effect on the subsequent mobility pattern. The relative risk ratios for the variables capturing neighbourhood ethnic composition in 1999 show that the ethnic composition of the initial neighbourhood has a modest effect. A higher concentration of Surinamese in the initial neigbourhood is associated with a smaller probability of moving into a less segregated neighbourhood, while a higher concentration of other non-western immigrants is positively associated with a slightly higher probability of moving into more segregated neighbourhoods.

The estimates also account for individual and neighbourhood characteristics. First, age and gender do not seem to play a prominent part in explaining the mobility of immigrants. There is some indication that older immigrants are less likely to move. These small effects are possibly the result of less variation in the age structure of immigrants: 31.9 on average in 
2000 for the population aged 18 years and older. The inhabitants of a rented dwelling are more likely to move to a more segregated neighbourhood. If renters live in a segregated neighbourhood, they are most unlikely to move. One-person households and couples without children are more likely to move, while couples with children are relatively less likely to move than households without children, which is in line with the internal migration literature. If couples with or without children move, they are more likely to choose a less segregated neighbourhood, and so are one-person households.

Immigrants in paid employment move more frequently and their destination is more likely to be a less segregated neighbourhood. Unemployed immigrants, in contrast, are likely to move into more segregated neighbourhoods. This outcome suggests that a weak labour market attachment usually accompanied by a poor socioeconomic position is associated with a higher probability of moving to a more segregated neighbourhood. Conversely, a stronger labour market attachment in terms of a job and associated with a greater accumulation of human and financial capital enables an individual to choose where to move more freely. These results clearly support the prediction of spatial assimilation theory, that social mobility can generate spatial mobility towards areas with a greater share of the dominant group.

To capture composition effects with regard to unemployment, two unemployment variables have been constructed: one for the entire labour force and one exclusively for the native Dutch labour force in the neighbourhood. Since these two variables are used in the models simultaneously, the coefficient for the first gives the effect of unemployment among the nonnative labour force on the probability of moving. In fact, the effects of these two variables are significantly different for residents of the three neighbourhood types. Greater unemployment among ethnic minorities is consistently positively associated with a greater probability of moving into a more segregated neighbourhood, while the converse holds for unemployment among the native Dutch labour force. Higher mean earnings in the neighbourhood do not 
generate a greater probability of moving to a less segregated neighbourhood. Higher earnings is associated with a lower probability of moving. A similar effect is observed for mean value of houses in the neighbourhood. House values in the neigbourhood seem to have a small negative effect on the probability of move, particularly in less segregated areas.

A neighbourhood is small in size and can hardly be seen as an independent local labour market. Unemployment and lower earnings in a neighbourhood therefore probably indicate a concentration of poor people rather than an unfavourable local labour market. In the Dutch context, municipalities can be seen more convincingly as local labour markets. Hence, unemployment in the municipality is also included in the models. A higher unemployment rate in the municipality is associated with a higher probability of moving to a more segregated neighbourhood for those who reside in a native neighbourhood. In addition to unemployment, we also controlled for the relative size of the medium- and highly-skilled labour force in the municipality, considering the share of low skilled as reference. An immigrant residing in a segregated neighbourhood associated with a higher share of the medium and highly skilled labour force carries a lower probability of moving in any direction. When the neighbourhood type is native with a higher share of medium skilled labour force, an immigrant has a lower probability of moving to more segregated neighbourhoods. Living in a municipality with a greater share of social housing seems to be associated with a greater probability of moving into a more segregated neighbourhood, but this effect is very small.

Finally, it is worth noting that the shift from less segregated to segregated neighbourhoods is very strong for immigrants living in The Hague, Rotterdam, Utrecht, and Amsterdam. This finding is in fact not surprising, since there are relatively many segregated neighbourhoods in the four largest cities. 


\section{$<$ TABLE 8>>}

\section{Robustness of the results}

To ensure the robustness of our results on residential relocations, we conducted some checks. First, we estimated models including unambiguously exogenous variables only, such as gender, age, ethnic origin, and migration motive. These restricted models provided more pronounced estimates for age and gender, but the general pattern of mobility towards more segregated neighbourhoods remained much the same. We also repeated all estimations for the separate populations of Turkish, Moroccan, and Surinamese immigrants. The results confirmed the mobility patterns found for these groups.

The pooled estimations impose, in effect, a uniform structure on the likelihood functions over the periods considered. This strategy may not be appropriate if in every subsequent year different factors are at work in determining location choices. Therefore, we alternatively estimated the transition probabilities for each separate year (2000-2003) given the location at time $t$ - 1 . The main results remained completely intact. An additional finding was that the probability of moving to a segregated neighbourhood among immigrant groups from nonwestern countries increased during the first three years from arrival, after which the probability stagnated. It is also striking that single-person households and couples without children tended to move to segregated neighbourhoods in the second year following arrival (the year 2000), regardless of the segregation level of their neighbourhood of origin. Moreover, an overwhelmingly large share of the moves among the inhabitants of the largest cities from native and segregated neighbourhoods occurred in the third and fifth years (2002 and 2003). 
Finally, we also estimated models for the first move only. These estimations provided results similar to those presented. This check ensures that the results are not biased by the presence of multiple movers (chronic movers; compare MORRISON, 1971).

\section{CONCLUSIONS}

The rise of ethnic concentrations in large European cities and the social problems associated with these concentrations require a better understanding of the mechanisms underlying ethnic residential segregation. This study provides empirical evidence on one important channel of segregation dynamics: the contribution of new immigrants to ethnic residential segregation in the Netherlands. The implications of the findings from this study are possibly also applicable to other European countries attracting a substantial number of immigrants.

Using a unique longitudinal database, this study examined the initial location settlement patterns, and subsequent relocations of the entire immigrant population arriving in the Netherlands in 1999. The study accounted for individual demographic and socioeconomic characteristics and neighbourhood characteristics as well as typical restrictions on the Dutch housing market. The evidence suggests that there is a substantial mobility of immigrants in the first years following arrival, particularly among immigrants from non-western countries. Non-western immigrants not only settle initially in more ethnically segregated neighbourhoods, but also tend to migrate to segregated neighbourhoods. The propensity to remigrate towards more segregated neighbourhoods is particularly strong in the four largest cities: The Hague, Rotterdam, Utrecht, and Amsterdam. This high mobility leads to a decline in the share of immigrants residing in native neighbourhoods within the first five years after immigration. The analysis has shown that initial location choice only explains a part of immigrant concentration 
The results also demonstrated distinct settlement trajectories for asylum migrants, other nonwestern migrants, and western immigrants in initial and subsequent settlement patterns. The settlement and mobility patterns of asylum migrants are markedly different from those of other migrants. They are initially much more diffused over the country, probably as a result of specific government settlement policies, and their settlement pattern is not sensitive to local economic conditions. However, in the course of time, asylum migrants show the strongest tendency of all migrant groups to move to more ethnically segregated neighbourhoods. This particularly strong tendency implies that government settlement policies designed to regulate only initial settlement locations have a limited impact and can hardly realise a diffusion of immigrants over the country.

Considering other non-refugee immigrants, the initial location of immigrants is more likely to be neighbourhoods where people from the same county of origin and some other ethnic groups are concentrated. The analysis confirms the main predictions of spatial assimilation theory with respect to different settlement and mobility patterns for western and non-western immigrant groups on the one hand and between non-western immigrant groups on the other. Western immigrants with a shorter distance from the native Dutch in terms of human capital, relevant language(s), socioeconomic position, and religion, who mainly entered as labour or family migrants, seem less likely to move into a more segregated neighbourhood. Among the immigrant groups with a large community in the Netherlands, Surinamese immigrants differ from Turkish and Moroccan immigrants, reflecting their relatively favourable socioeconomic position, their mastery of the Dutch language, and cultural similarities with native Dutch. Their initial settlement pattern is likely to be unaffected by the ethnic composition of the neighbourhood; their spatial mobility is not in a one-way direction, whereas the subsequent mobility of Turkish and Moroccan immigrants appears to be mainly towards more segregated neighbourhoods. The probability of moving from a more to a less segregated neighbourhood 
is low for Turkish and Moroccan immigrants, or at least it was in the five years observed. A slightly lower tendency of moving into more segregated neighbourhoods for Turkish than for Moroccan immigrants might have stemmed from the differences in the socioeconomic positions of these two groups.

A favourable economic condition of the neighbourhood in terms of low unemployment and average high earnings is positively associated more with immigrants who entered the Netherlands as labour or family migrants. Looking at the socioeconomic position of the immigrant, having a job goes with a greater probability of moving, and these moves are more likely to be directed towards less segregated neighbourhoods. We have shown that the impact of unemployment on native Dutch and ethnic minorities in the neighbourhood is fundamentally different. While more ethnic minority unemployment is associated with a greater probability of moving into more segregated neighbourhoods, the unemployment among natives seems, on the contrary, to be associated with a greater probability of moving towards less segregated neighbourhoods. Finally, those who live in a rented home have a greater probability of moving into a more segregated neighbourhood. The housing market rigidities seem to generate no different effects across the groups of immigrants who arrived in the same year. 


\section{REFERENCES}

ANDERSSON, R. (1998). Socio-spatial dynamics: Ethnic divisions of mobility and housing in post-Palme Sweden. Urban Studies, 35, 3, 397-428

ASLUND, O. (2005). Now and forever? Initial and subsequent location choices of immigrants. Regional Science and Urban Economics, 35, 141-165

BARTEL, A.P. (1989). Where do the new United States immigrants live? Journal of Labour Economics, 7, 371-391

BEENSTOCK , M. (1997). The internal migration of immigrants: Israel 1969-1972. The Quarterly Review of Economics and Finance, 37, Special Issue, 263-284

BOLT, G. \& VAN KEMPEN, R. (2003). Escaping poverty neighbourhoods in the Netherlands. Housing, Theory and Society, 20, 209-222

BORJAS, G.J. (1998). To ghetto or not to ghetto: ethnicity and residential segregation. Journal of Urban Economics, 44, 228-253

BORJAS, G.J. (1999). Immigration and welfare magnets. Journal of Labor Economics, 17, 4, 607-637

CUTLER, D.M., GLAESER, E.L. \& VIGDOR, J.L. (1999). The rise and decline of the American ghetto. Journal of Political Economy, 112, 827-872

FONG, E. \& WILKES, R. (1999). The spatial assimilation model re-examined: an assessment by Canadian data. International Migration Review, 33, 3, 594-620

FUNKHOUSER, E. (2000). Changes in the geographic concentration and location of residence of immigrants. International Migration Review, 34, 2, 489-510

HARTOG, J. \& A. ZORLU (2005). How Important Is Homeland Education for Refugees' Economic Position in The Netherlands? IZA Discussion paper 1753 
KAUSHAL, N. (2005). New immigrants' location choices: magnets without welfare. Journal of Labor Economics, 23, 1, 59-80

LOGAN, J.R., ALBA, R.D. \& ZWANG, W. (2002). Immigrant enclaves and ethnic communities in New York and Los Angeles. American Sociological Review, 67, 2, 299-322

MASSEY,, D.S., GROSS, A.B. \& SHIBUYA, K. (1994). Migration, segregation and the geographic concentration of poverty. American Sociological Review, 59, 425-445

MASSEY, D.S. \& DENTON, N.A. (1993). American apartheid: segregation and the making of the underclass. Harvard University Press, Cambridge, MA.

MASSEY, D.S. \& DENTON, N.A. (1985). Spatial assimilation as a socioeconomic outcome. American Sociological Review, 50, 94-106

MASSEY, D.S. \& MULLAN, B.P. (1984). Processes of Hispanic and black spatial assimilation. The American Journal of Sociological, 89, 4, 836-873

MORRISON, P. A. (1971). Chronic movers and the future redistribution of population: A longitudinal analysis. Demography, 8, 2, 171-184.

MUSTERD, S. \& DE VOS, S. (2005). Woondynamiek in concentratiewijken, in MULDER, C.M and PINKSTER, F.M. (Eds) Onderscheid in Wonen. Het Sociale van Binnen en Buiten, 123-138. Amsterdam University Press, Amsterdam

MUSTERD, S. (2005). Social and ethnic segregation in Europe: levels, causes and effects. Journal of Urban Affairs, 27, 3, 331-348

MUSTERD, S. (2003). Segregation and integration: a contested relationship. Journal of Ethnic and Migration Studies, 29, 4, 623-641

NOGLE, J.M. (1994). Internal migration for recent immigrants to Canada. International Migration Review, 28, 1, 31-48 
QUILLIAN, L. (2002). Why is black-white residential segregation so persistent?: Evidence on three theories from migration data. Social Science Research, 31, 197-229

SOUTH, S.J., CROWDER, K. \& CHAVEZ, E. (2005). Migration and Spatial assimilation among U.S. Latinos: classical versus segmented trajectories. Demography, 42, 497-521.

SOUTH, S.J. \& CROWDER, K. (1998). Leaving the 'hood': Residential mobility between black, white and integrated neighborhoods. American Sociological Review, 63, 1, 17-26

ZAVODNY, M. (1999). Determinants of recent immigrants' location choices. International Migration Review, 33, 4, 1014-1030

ZORLU, A. \& HARTOG, J. (2002). Migration and immigrants: The case of the Netherlands. In ROTTE R. and STEIN, P. (Eds) Migration Policy and the Economy: International experiences, Munchen: Hans Seidel Stiftung. 
Table 1 . Mean values of covariates by country of birth, 2000

\begin{tabular}{|c|c|c|c|c|c|c|c|c|}
\hline & Afghani. & China & Iraq & Turkey & Morocco & Surinam & $\begin{array}{l}\text { Oth.non- } \\
\text { western }\end{array}$ & Western \\
\hline Female & 0.42 & 0.51 & 0.41 & 0.50 & 0.50 & 0.57 & 0.48 & 0.50 \\
\hline Age & 24.91 & 24.75 & 25.49 & 25.03 & 25.68 & 27.18 & 26.47 & 28.61 \\
\hline Renter & 0.92 & 0.61 & 0.83 & 0.78 & 0.87 & 0.74 & 0.66 & 0.58 \\
\hline Single-person household & 0.16 & 0.38 & 0.27 & 0.11 & 0.12 & 0.16 & 0.30 & 0.28 \\
\hline Couple no child & 0.05 & 0.17 & 0.08 & 0.34 & 0.31 & 0.23 & 0.17 & 0.21 \\
\hline Couple with children & 0.36 & 0.23 & 0.42 & 0.45 & 0.47 & 0.34 & 0.28 & 0.28 \\
\hline Employed & 0.20 & 0.25 & 0.14 & 0.43 & 0.41 & 0.50 & 0.27 & 0.43 \\
\hline Unemployed & 0.10 & 0.04 & 0.14 & 0.08 & 0.09 & 0.06 & 0.08 & 0.03 \\
\hline Labour migrant & 0.00 & 0.12 & 0.00 & 0.04 & 0.03 & 0.02 & 0.11 & 0.37 \\
\hline sylu & 0.88 & 0.35 & 0.68 & 0.09 & 0.02 & 0.02 & 0.36 & 0.13 \\
\hline Fam & 0.11 & 0.17 & 0.29 & 0.32 & 0.38 & 0.37 & 0.21 & 0.22 \\
\hline Family for & 0.01 & 0.14 & 0.02 & 0.53 & 0.49 & 0.46 & 0.19 & 0.11 \\
\hline Studer & 0.00 & 0.18 & 0.00 & 0.01 & 0.06 & .09 & 9 & 0.10 \\
\hline Othe & 0.00 & 03 & 00 & 0.01 & 0.01 & .04 & .04 & 0.07 \\
\hline Amst & 0.06 & 0.07 & 0.03 & 0.12 & 0.24 & 28 & 12 & 0.12 \\
\hline Rotterdam & 0.04 & 13 & 05 & 11 & 0.11 & 17 & 08 & 0.06 \\
\hline igue & 0.03 & 0.07 & 0.06 & 0. & 0.08 & 0.12 & 0.08 & 0.06 \\
\hline Utrecht & 0.02 & 0.03 & 0.02 & 0.03 & 0.07 & 0.02 & 0.02 & 0.03 \\
\hline Neigb & 4.94 & 5.18 & 4.09 & 6.17 & 7.26 & 10.19 & 5.73 & 4.87 \\
\hline Mean u & 21817 & 21751 & 21116 & 19990 & 20336 & 21107 & 22538 & 24996 \\
\hline$\%$ Socia & 36.35 & 42.65 & 37.27 & 42.72 & 45.10 & 46.09 & 40.82 & 39.19 \\
\hline unicip. (x1000) & 81.46 & 71.64 & 77.19 & 70.50 & 71.48 & 68.85 & 75.05 & 79.10 \\
\hline Unemployme & 3.53 & 4.26 & 3.85 & 4.25 & 4.49 & 4.67 & 4.14 & 3.99 \\
\hline$\%$ Med & 43.39 & 39.66 & 43.54 & 40.52 & 37.89 & 38.09 & 40.64 & 40.53 \\
\hline$\%$ High edu. lab. force in $n$ & 27.86 & 32.77 & 27.91 & 30.60 & 35.07 & 34.32 & 31.71 & 32.36 \\
\hline$\pi 170$ & 5360 & 1435 & 3132 & 4536 & 4716 & 1588 & 17118 & 31737 \\
\hline$\%$ Not present in 2003 & 2 & 16 & 8 & 6 & 5 & 5 & 21 & 33 \\
\hline
\end{tabular}


Table 2. Determinants of immigrants' location choices by country of birth; regression estimates with robust standard errors

\begin{tabular}{|c|c|c|c|c|c|c|c|c|c|c|c|c|c|c|}
\hline & Moroc. & & Turkey & & Surinam & & Afghan. & & China & & Iraq & & Western & \\
\hline & Coefficient & Beta & Coefficient & Beta & Coefficient & Beta & Coefficient & Beta & Coefficient & Beta & Coefficient & Beta & Coefficient & Beta \\
\hline \multicolumn{15}{|c|}{ Neighbourhood Characteristics } \\
\hline$\%$ Moroccans & $0.526^{* *}$ & 0.39 & $0.177^{*}$ & 0.16 & -0.054 & -0.06 & 0.022 & 0.03 & -0.011 & -0.04 & -0.006 & -0.01 & -0.292 & -0.07 \\
\hline$\%$ Turks & 0.025 & 0.02 & $0.202^{* *}$ & 0.24 & -0.017 & -0.03 & -0.019 & -0.03 & -0.005 & -0.02 & 0.004 & 0.01 & $-0.112^{* \star}$ & -0.03 \\
\hline$\%$ Surinam/Antillean & $0.082 *$ & 0.08 & 0.063 & 0.07 & 0.301 & 0.44 & -0.016 & -0.02 & 0.014 * & 0.06 & $-0.054 *$ & -0.09 & $-0.341^{\star * *}$ & -0.10 \\
\hline$\%$ Other non-western & -0.007 & -0.01 & 0.008 & 0.01 & 0.021 & 0.03 & $0.111^{\star *}$ & 0.17 & $0.018^{*}$ & 0.08 & $0.161^{\star \star}$ & 0.28 & $0.409 * * *$ & 0.12 \\
\hline$\%$ Western & $-0.030^{*}$ & -0.05 & -0.019 & -0.04 & -0.026 & -0.07 & -0.012 & -0.03 & -0.001 & -0.01 & -0.009 & -0.03 & $0.321^{* * *}$ & 0.17 \\
\hline$\%$ Home owners & $0.016^{* *}$ & 0.12 & $0.015^{\star *}$ & 0.13 & 0.010 & 0.11 & 0.000 & 0.00 & $0.001 *$ & 0.04 & 0.002 & 0.02 & 0.001 & 0.00 \\
\hline Log mean wages & 0.249 & 0.02 & 0.254 & 0.02 & -0.275 & -0.03 & $0.271^{*}$ & 0.03 & -0.080 & -0.02 & 0.004 & 0.00 & 2.148 & 0.04 \\
\hline Log mean value of houses & $-1.196^{* * *}$ & -1.64 & $-1.361^{* * *}$ & -2.19 & $-0.219^{* * *}$ & -0.47 & $-0.690 * * *$ & -1.49 & $-0.224^{* * *}$ & -1.33 & $-0.471^{* * *}$ & -1.15 & $-1.037^{*}$ & -0.43 \\
\hline Population (in1000s) & $0.252^{* *}$ & 0.18 & $0.174^{* \star *}$ & 0.14 & 0.204 & 0.22 & $0.218^{* \star *}$ & 0.24 & $0.055^{\star * *}$ & 0.17 & $0.084^{* * *}$ & 0.11 & $1.098^{* * *}$ & 0.24 \\
\hline \multicolumn{15}{|l|}{ Municipality Characteristics } \\
\hline Population (in1000s) & -0.001 & -0.05 & -0.001 & -0.04 & -0.002 & -0.11 & -0.001 & -0.08 & 0.000 & -0.06 & -0.001 & -0.07 & -0.002 & -0.02 \\
\hline$\%$ Social housing & -0.006 & -0.02 & 0.000 & 0.00 & -0.008 & -0.04 & $-0.01 *$ & -0.05 & 0.002 & 0.02 & 0.000 & 0.00 & 0.003 & 0.00 \\
\hline$\%$ Med. skilled labour force & 0.001 & 0.00 & 0.003 & 0.01 & -0.010 & -0.03 & -0.007 & -0.02 & -0.003 & -0.03 & 0.004 & 0.01 & -0.041 & -0.03 \\
\hline$\%$ Higher skilled labour force & 0.010 * & 0.03 & 0.009 & 0.03 & -0.003 & -0.01 & 0.001 & 0.01 & $0.008^{* * *}$ & 0.11 & 0.005 & 0.03 & 0.080 * & 0.07 \\
\hline Unemployment rate & $-0.055^{\star \star}$ & -0.02 & $-0.098^{* \star *}$ & -0.05 & -0.014 & -0.01 & $-0.054^{\star *}$ & -0.04 & 0.001 & 0.00 & -0.003 & 0.00 & -0.010 & 0.00 \\
\hline Amsterdam & $8.687^{* * *}$ & 0.31 & $3.999 * * *$ & 0.17 & $4.365^{* * *}$ & 0.24 & 1.528 ** & 0.09 & $0.532 *$ & 0.08 & 0.451 & 0.03 & $29.191^{* * *}$ & 0.32 \\
\hline Rotterdam & $3.977^{* * *}$ & 0.12 & $3.902 * * *$ & 0.14 & 1.349 & 0.06 & 0.586 & 0.03 & $1.172^{* \star \star}$ & 0.15 & 0.568 & 0.03 & $14.450^{* * *}$ & 0.13 \\
\hline The Hague & $1.871^{* \star *}$ & 0.07 & $3.355^{* * *}$ & 0.16 & -0.200 & -0.01 & 0.329 & 0.02 & $0.385^{*}$ & 0.07 & $1.251^{\star \star \star}$ & 0.09 & $14.642^{* \star *}$ & 0.18 \\
\hline Utrecht & 0.975 & 0.03 & -0.161 & -0.01 & 0.300 & 0.02 & 0.016 & 0.00 & -0.017 & 0.00 & 0.147 & 0.01 & 3.900 ** & 0.04 \\
\hline Intercept & $9.835^{\star * *}$ & & $\overline{11.741}$ *** & & 5.062 & & $6.147^{\overline{* *}}$ & & $3.212^{* * *}$ & & $5.013^{\star \star}$ & & -10.851 & \\
\hline R-squared & 0.45 & & 0.33 & & 0.29 & & 0.12 & & 0.15 & & 0.09 & & 0.36 & \\
\hline $\mathrm{N}$ neighbourhoods & 8275 & & 8275 & & 8275 & & 8275 & & 8275 & & 8275 & & 8275 & \\
\hline
\end{tabular}

$\mathrm{p}<.05 ; * * \mathrm{p}<.01 ; * * * \mathrm{p}<.001$ 
Table 3. Determinants of immigrants' location choices by migration motive; regression estimates with robust standard errors

\begin{tabular}{|c|c|c|c|c|c|c|c|c|c|c|c|c|c|c|c|c|}
\hline & \multirow{2}{*}{\multicolumn{2}{|c|}{ Labour }} & \multicolumn{2}{|l|}{ Asylum } & \multicolumn{4}{|l|}{ Turkey } & \multicolumn{4}{|l|}{ Morocco } & \multicolumn{4}{|l|}{ Surinam } \\
\hline & & & & & \multicolumn{2}{|c|}{ Family reunify. } & \multicolumn{2}{|c|}{ Family form. } & \multicolumn{2}{|c|}{ Family reunify. } & \multicolumn{2}{|c|}{ Family form. } & \multicolumn{2}{|c|}{ Family reunify. } & \multicolumn{2}{|c|}{ Family form. } \\
\hline & Coefficient & Betal & Coefficient & Betal & Coefficient & Beta C & pefficient & Beta & Coefficient & Beta & efficient & Betal & Coefficient & BetaC & efficient & Beta \\
\hline \multicolumn{17}{|l|}{ Neighbourhood Characteristics } \\
\hline$\%$ Moroccans & -0.149 & -0.05 & -0.043 & -0.01 & $0.050 *$ & 0.11 & $0.101^{\star}$ & 0.17 & $0.173^{* *}$ & 0.31 & $0.255^{\star *}$ & 0.41 & $-0.023-$ & -0.07 & -0.019 & -0.05 \\
\hline$\%$ Turks & 0.024 & 0.01 & 0.054 & 0.02 & $0.071^{*}$ & 0.20 & $0.105^{* * *}$ & * 0.24 & 0.014 & 0.03 & 0.007 & 0.01 & $-0.002-$ & -0.01 & -0.007 & -0.02 \\
\hline$\%$ Surinam/Antillean & -0.170 & -0.08 & $-0.405^{* *}$ & -0.16 & 0.044 & 0.12 & 0.008 & 0.02 & $0.050^{*}$ & 0.12 & 0.013 & 0.03 & 0.107 & 0.42 & 0.135 & 0.42 \\
\hline$\%$ Other non-western & $0.186^{*}$ & 0.09 & $1.459^{* * *}$ & 0.61 & -0.007 & -0.02 & -0.002 & 0.00 & $-0.004-$ & -0.01 & -0.004 & -0.01 & 0.006 & 0.03 & 0.010 & 0.03 \\
\hline$\%$ Western & $0.141^{* * *}$ & 0.12 & -0.062 & -0.04 & -0.008 & -0.04 & $-0.009 *$ & -0.03 & $-0.012 *-$ & -0.05 & -0.013 & -0.05 & $-0.009-$ & -0.06 & -0.013 & -0.07 \\
\hline$\%$ Home owners & 0.001 & 0.00 & 0.007 & 0.02 & 0.006 * & 0.11 & $0.007^{* *}$ & 0.12 & $0.007^{* *}$ & 0.12 & $0.006 *$ & 0.09 & $0.004^{*}$ & 0.11 & 0.005 & 0.11 \\
\hline Log & $2.240 *$ & 0.07 & -1.030 & -0.03 & 0.022 & 0.00 & $0.203^{* \star}$ & 0.03 & -0.001 & 0.00 & $0.229^{* \star}$ & 0.03 & $-0.110-$ & -0.03 & -0.123 & -0.03 \\
\hline Log & 0.294 & 0.20 & 0.023 & 0.01 & $-0.413^{* * *}$ & -1.61 & $-0.770^{* * *}$ & * -2.40 & $-0.407^{* * *}-$ & -1.35 & $-0.561^{* * *}$ & -1.66 & $-0.062^{\star * *}-$ & ${ }^{*}-0.35$ & $-0.117^{* * *}$ & * -0.53 \\
\hline Population (in 1000 s & $0.812^{* * *}$ & 0.28 & $6^{* * *}$ & 0.30 & 0.050 ** & 0.10 & $0.084^{* * *}$ & ${ }^{*} 0.13$ & $0.088^{* *}$ & 0.15 & $0.113^{*}$ & 0.17 & $0.070^{*}$ & 0.20 & 0.093 & 0.22 \\
\hline \multicolumn{17}{|l|}{ Municipality Characteristics } \\
\hline Population (in 1000s) & $\overline{0.016}$ & 0.28 & -0.006 & -0.09 & -0.001 & -0.09 & 0.000 & 0.03 & -0.001 & -0.07 & 0.000 & -0.03 & $-0.001-$ & -0.11 & -0.001 & -0.12 \\
\hline \% Social housing & -0.005 & -0.01 & -0.024 & -0.03 & -0.001 & -0.01 & 0.001 & 0.01 & -0.003 & -0.02 & -0.002 & -0.01 & $-0.003-$ & -0.03 & -0.004 & -0.04 \\
\hline$\% N$ & 0.009 & 0.01 & 0.005 & 0.00 & 0.002 & 0.01 & 0.001 & 0.00 & 0.001 & 0.01 & -0.001 & -0.01 & $-0.003-$ & -0.03 & -0.005 & -0.03 \\
\hline$\%$ & 0.012 & 0.02 & -0.027 & -0.03 & $0.005^{*}$ & 0.04 & 0.003 & 0.02 & $5^{*}$ & 0.03 & 0.003 & 0.02 & $-0.001-$ & -0.01 & -0.002 & -0.02 \\
\hline Unemployment rate & -0.057 & -0.01 & $0.243^{* *}$ & 0.04 & -0.028 ** & -0.03 & $-0.066^{* * *}$ & ${ }^{*}-0.06$ & -0.015 & -0.01 & $-0.030 * *$ & -0.03 & $-0.006-$ & -0.01 & -0.005 & -0.01 \\
\hline Amsterdam & 7.855 & 0.14 & 1.447 & 0.02 & $1.410^{\star \star \star}$ & 0.14 & $1.553^{* \star *}$ & * 0.13 & $2.554^{\star \star \star}$ & 0.22 & $3.740^{* \star *}$ & 0.29 & $1.378^{\star \star *}$ & 0.20 & $2.228^{* \star *}$ & * 0.26 \\
\hline Rotterdam & -0.948 & -0.01 & 1.656 & 0.02 & $1.709^{\star \star \star}$ & 0.15 & $1.454^{* * *}$ & * 0.10 & $2.093^{* * *}$ & 0.15 & $1.371^{* * *}$ & 0.09 & 0.522 & 0.06 & 0.505 & 0.05 \\
\hline The Hague & -0.649 & -0.01 & $3.672^{* *}$ & 0.06 & $1.933^{* * *}$ & 0.22 & 0.638 * & 0.06 & $1.231^{* \star *}$ & 0.12 & 0.217 & 0.02 & $-0.036-$ & -0.01 & -0.143 & -0.02 \\
\hline Utrecht & -0.759 & -0.01 & 0.639 & 0.01 & -0.139 & -0.01 & -0.100 & -0.01 & 0.294 & 0.02 & 0.577 & 0.04 & 0.066 & 0.01 & 0.138 & 0.02 \\
\hline Intercept & -28.120 * & & 8.846 & & 3.960 ** & & $6.234^{\overline{* \star *}}$ & & $4.004^{* *}$ & & $3.739^{\overline{* \star}}$ & & 1.719 & & 2.506 & \\
\hline R-squared & 0.32 & & 0.38 & & 0.24 & & 0.29 & & 0.32 & & 0.42 & & 0.28 & & 0.25 & \\
\hline N neighbourhoods & 8275 & & 8275 & & 8275 & & 8275 & & 8275 & & 8275 & & 8275 & & 8275 & \\
\hline
\end{tabular}

$\mathrm{p}<.05 ; * * \mathrm{p}<.01 ; * * * \mathrm{p}<.001$ 
Table 4. Percentage of movers within and between municipalities by country of birth and migration motive, 1999-2003

\begin{tabular}{|c|c|c|c|c|c|c|c|c|c|c|c|c|}
\hline & \multicolumn{4}{|c|}{ WITHIN MUNICIPALITY } & \multicolumn{4}{|c|}{$\begin{array}{r}\text { BETWEEN } \\
\text { NICIPALITIES }\end{array}$} & \multicolumn{4}{|c|}{ TOTAL } \\
\hline & 2000 & 2001 & 2002 & 2003 & 2000 & 2001 & 2002 & 2003 & 2000 & 2001 & 2002 & 2003 \\
\hline \multicolumn{13}{|l|}{ Country of birth } \\
\hline Afghanistan & 5.60 & 12.28 & 11.44 & 7.31 & 9.62 & 8.66 & 6.89 & 6.15 & 15.22 & 20.94 & 18.33 & 13.46 \\
\hline China & 8.89 & 13.88 & 14.04 & 14.27 & 15.14 & 19.73 & 16.09 & 11.09 & 24.03 & 33.62 & 30.13 & 25.37 \\
\hline Iraq & 7.30 & 11.89 & 10.88 & 9.66 & 9.37 & 16.19 & 15.41 & 13.45 & 16.67 & 28.08 & 26.30 & 23.11 \\
\hline Turkey & 11.78 & 15.48 & 14.73 & 14.95 & 4.14 & 4.80 & 4.45 & 3.45 & 15.91 & 20.28 & 19.18 & 18.40 \\
\hline Morocco & 11.70 & 13.64 & 13.10 & 12.55 & 3.15 & 3.51 & 3.43 & 3.59 & 14.85 & 17.15 & 16.53 & 16.14 \\
\hline Surinam & 14.16 & 20.30 & 16.76 & 13.03 & 7.50 & 8.91 & 7.34 & 7.23 & 21.65 & 29.21 & 24.10 & 20.26 \\
\hline Oth.Non-west & 8.91 & 12.64 & 12.87 & 12.08 & 8.67 & 11.11 & 9.13 & 7.56 & 17.58 & 23.75 & 21.99 & 19.64 \\
\hline Western & 7.14 & 9.80 & 8.90 & 7.38 & 5.88 & 8.87 & 7.91 & 6.08 & 13.01 & 18.66 & 16.81 & 13.45 \\
\hline \multicolumn{13}{|l|}{ Migration motive } \\
\hline Labour & 9.57 & 12.44 & 10.98 & 8.63 & 6.30 & 8.07 & 7.09 & 5.55 & 15.88 & 20.51 & 18.07 & 14.18 \\
\hline Asylum & 7.32 & 13.22 & 13.00 & 10.75 & 12.60 & 16.62 & 13.44 & 10.02 & 19.92 & 29.84 & 26.45 & 20.77 \\
\hline Family reunification & 7.99 & 10.31 & 9.82 & 9.51 & 4.68 & 5.57 & 5.40 & 5.00 & 12.67 & 15.88 & 15.22 & 14.51 \\
\hline Family formation & 9.47 & 12.34 & 11.94 & 11.65 & 3.75 & 5.34 & 4.78 & 4.43 & 13.22 & 17.67 & 16.72 & 16.08 \\
\hline Education & 8.85 & 11.77 & 10.95 & 8.61 & 4.40 & 7.28 & 7.34 & 6.56 & 13.25 & 19.05 & 18.30 & 15.17 \\
\hline Other & 4.30 & 6.40 & 6.20 & 5.47 & 4.22 & 5.58 & 3.64 & 3.95 & 8.52 & 11.98 & 9.84 & 9.42 \\
\hline Total & 8.31 & 11.89 & 11.36 & 10.06 & 6.96 & 9.30 & 8.04 & 6.57 & 15.27 & 21.19 & 19.40 & 16.63 \\
\hline
\end{tabular}


Table 5. Neighbourhood type origin-destination matrix, mover person-years only, by country of birth and migration motive, 1999-2003, percentages

\begin{tabular}{|c|c|c|c|c|c|c|c|c|c|c|c|c|}
\hline & \multicolumn{3}{|c|}{ From native to } & \multicolumn{3}{|c|}{ From mixed to } & \multicolumn{3}{|c|}{ From segreg. to } & \multicolumn{3}{|c|}{ N Movers from } \\
\hline & Native & Mixed & Segre & Native & Mixed & Segre & Native & Mixed & Segre & Native & Mixed & $\overline{\text { Segre }}$ \\
\hline \multicolumn{13}{|c|}{ Country of origin } \\
\hline$\overline{\text { Afghanistan }}$ & 49.10 & 36.80 & 14.83 & .28 & 53.06 & 22.66 & 17.66 & 33.23 & 49.10 & 1,774 & 1,112 & 668 \\
\hline China & 52.50 & 33.83 & 13.68 & 30.77 & 46.85 & 22.38 & 12.33 & 26.00 & 61.67 & 541 & 572 & 300 \\
\hline Iraq & 51.54 & 34.05 & 14.41 & 28.78 & 50.15 & 21.07 & 22.60 & 40.24 & 37.16 & 1,166 & 973 & 584 \\
\hline Turkey & 55.74 & 35.01 & 9.24 & 6.18 & 63.07 & 20.75 & 6.98 & 21.67 & 71.35 & 714 & 1,205 & 1,246 \\
\hline Morocco & 51.15 & 34.54 & 14.31 & 3.44 & 56.59 & 29.97 & 5.25 & 24.28 & 70.46 & 524 & 1,131 & 1,256 \\
\hline & 35.36 & 44 & 20.44 & 0.83 & 51.46 & 37.71 & 5.87 & 26.95 & 67. & 181 & 480 & 783 \\
\hline$n-w$ & 50.93 & 3 & 14.06 & 28.72 & 51.25 & 20.02 & 14.88 & 28.16 & 56 & 4,644 & 4,310 & 2,816 \\
\hline stern & 67.01 & 26. & 6 & 36.64 & 51.31 & 12.05 & 25.88 & 39.05 & 35.08 & 7,730 & 4,845 & 1,913 \\
\hline \multicolumn{13}{|c|}{ Migration motive } \\
\hline & 66.45 & 28.84 & & .77 & & & 18.34 & 35 & 48 & 3,401 & 2,465 & 938 \\
\hline & 50.23 & 34 & 15.6 & 29.58 & 48.67 & 21.75 & 21.47 & 33 & 45 & 7,382 & 5,521 & 3,475 \\
\hline y rel & 64.85 & 28.46 & 6.69 & 24.76 & 54.86 & 20.38 & 9.32 & 25.44 & 65.24 & 3,078 & 2,552 & 2,178 \\
\hline Family form & 61.96 & 29.94 & 8.10 & 24.05 & 57.41 & 18.54 & 8.08 & 26.59 & 65.33 & 2,258 & 2,794 & 2,377 \\
\hline Study & 51.34 & 37.83 & 10.83 & 24.84 & 56.42 & 18.74 & 13.78 & 35.07 & 51.15 & 711 & 1,067 & 479 \\
\hline Other & 68.24 & 26.13 & 5.63 & 34.5 & 48.03 & 17.47 & 17.65 & 29.41 & 52.94 & 444 & 229 & 119 \\
\hline
\end{tabular}

Native, mixed, and segregated neighbourhoods indicate the share of ethnic minorities from non-western countries in the neighbourhood as up to 10 percent, 11 to 34 percent, and more than 35 respectively. 
Table 6. Neighbourhood type origin-destination matrix, mover person-years only, by country of birth, 1999-2003, percentages

\begin{tabular}{|c|c|c|c|c|c|c|c|c|c|}
\hline & \multicolumn{3}{|c|}{ From native to } & \multicolumn{3}{|c|}{ From mixed to } & \multicolumn{3}{|c|}{ From segreg. to } \\
\hline & Native & Mixed & Segreg. & Native & Mixed & Segreg. & Native & Mixed & Segreg. \\
\hline \multicolumn{10}{|c|}{ WITHIN MUNICIPALITY } \\
\hline Afghanistan & 66.36 & 29.50 & 4.14 & 14.24 & 62.50 & 23.26 & 6.44 & 33.56 & 60.00 \\
\hline China & 61.80 & 32.58 & 5.62 & 24.43 & 56.87 & 18.70 & 4.10 & 23.08 & 72.82 \\
\hline Iraq & 64.21 & 27.92 & 7.87 & 23.17 & 57.83 & 19.00 & 12.00 & 34.18 & 53.82 \\
\hline Turkey & 64.27 & 29.74 & 6.00 & 12.95 & 67.58 & 19.47 & 3.33 & 17.95 & 78.72 \\
\hline Morocco & 56.88 & 34.25 & 8.87 & 9.09 & 61.05 & 29.85 & 2.52 & 20.34 & 77.15 \\
\hline Surinam & 57.33 & 34.67 & 8.00 & 6.21 & 57.45 & 36.34 & 1.57 & 16.70 & 81.74 \\
\hline Oth.Non-west & 61.78 & 32.39 & 5.83 & 21.22 & 59.48 & 19.30 & 5.50 & 22.77 & 71.73 \\
\hline Western & 73.67 & 22.79 & 3.53 & 28.18 & 59.84 & 11.98 & 15.07 & 32.67 & 52.26 \\
\hline \multicolumn{10}{|c|}{ BETWEEN MUNICIPALITY } \\
\hline Afghanistan & 35.70 & 41.20 & 23.10 & 40.57 & 37.74 & 21.70 & 40.83 & 32.57 & 26.61 \\
\hline China & 47.93 & 34.44 & 17.63 & 36.13 & 38.39 & 25.48 & 27.62 & 31.43 & 40.95 \\
\hline Iraq & 45.14 & 37.09 & 17.77 & 34.28 & 42.80 & 22.92 & 32.25 & 45.93 & 21.82 \\
\hline Turkey & 43.77 & 42.42 & 13.80 & 28.24 & 46.27 & 25.49 & 30.91 & 46.06 & 23.03 \\
\hline Morocco & 41.03 & 35.38 & 23.59 & 30.21 & 38.72 & 31.06 & 21.20 & 47.28 & 31.52 \\
\hline Surinam & 19.81 & 50.94 & 29.25 & 20.25 & 39.24 & 40.51 & 16.18 & 56.37 & 27.45 \\
\hline Oth.Non-west & 42.51 & 37.11 & 20.38 & 39.45 & 39.39 & 21.16 & 36.84 & 41.30 & 21.86 \\
\hline Western & 60.03 & 31.33 & 8.64 & 49.16 & 38.60 & 12.24 & 39.46 & 46.88 & 13.66 \\
\hline
\end{tabular}


Table 7. Non-movers and change in the distribution of immigrants across the neighbourhood types between 1999 and 2003 by country of birth

\begin{tabular}{|c|c|c|c|c|c|c|}
\hline & \multicolumn{3}{|c|}{$\begin{array}{l}\text { Distribution of immigrants } \\
\text { upon arrival, } 1999\end{array}$} & \multicolumn{3}{|c|}{$\begin{array}{l}\text { Change in relative share, } \\
1999-2003\end{array}$} \\
\hline & Native & Mixed & $\overline{\text { Segreg. }}$ & Native & Mixed & egreg. \\
\hline Afghanistan & 3097 & 1543 & 684 & -10.8 & 7.2 & 3.5 \\
\hline China & 551 & 668 & 210 & -2.8 & -5.3 & 8.1 \\
\hline Iraq & 1342 & 1081 & 648 & -5.6 & 4.4 & 1.1 \\
\hline Turkey & 961 & 1768 & 1777 & -2.5 & 1.7 & 0.8 \\
\hline Morocco & 797 & 1843 & 2043 & -1.7 & 0.3 & 1.5 \\
\hline Surinam & 262 & 521 & 800 & -1.4 & 4.3 & -2.8 \\
\hline Other non-west. & 7212 & 6303 & 3375 & -5.5 & 1.1 & 4.5 \\
\hline Western & 18142 & 9631 & 3035 & -3.5 & 2.9 & 0.6 \\
\hline Total & 32364 & 23358 & 12572 & -33.9 & 16.6 & 17.3 \\
\hline
\end{tabular}




\section{Page 45 of 48}

Regional Studies

http://mc.manuscriptcentral.com/cres Email: regional.studies@fm.ru.nl 


\section{Page 47 of 48}

\section{Regional Studies}

$\mathrm{p}<.05 ; * * \mathrm{p}<.01 ; * * * \mathrm{p}<.001$

The multinomial logit model has 4 outcome categories: native, mixed, segregated neighbourhoods and staying, which is the reference category. The transition probabilities are separately estimated for the sub-samples of native, mixed, segregated neighbourhoods. 


\footnotetext{
${ }^{\mathrm{i}}$ The first year upon arrival may be seen as an adjustment year for new immigrants, who often spend some time learning the Dutch language and getting to know the Dutch labour market.

${ }^{\text {ii }}$ For instance; among labour migrants circa 20 percent of non-employed individuals and the presence of people aged under 18 may imply a measurement error.
} 